\title{
natureINSIGHT DYNAMICS OF THE CELL
}

21 July 2011 / Vol 475 / Issue No 7356

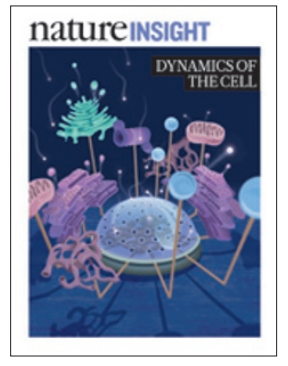

Cover illustration by Nik Spencer

\section{Editor, Nature}

Philip Campbell

Publishing

Nick Campbell

Insights Editor

Ursula Weiss

Production Editor

Nicola Bailey

Senior Art Editor

Kelly Buckheit Krause

Art Editor

Nik Spencer

Sponsorship

Gerard Preston

Yvette Smith

Production

Emilia Orviss

Marketing

Elena Woodstock

Hannah Phipps

Editorial Assistant

Hazel Mayhew
$A$ dvances in imaging in the past decade have revolutionized the field of cell biology.

Developments such as super-resolution fluorescence microscopy and the ability to detect single molecules mean that molecular and organelle dynamics can now be visualized at very high temporal and spatial resolution within living cells, allowing the processes to be studied with unprecedented detail and precision.

It is becoming clear that the central dogma of molecular biology - DNA makes RNA makes protein - is overly simplistic. Gene-Wei Li and Sunney Xie look at how single-molecule microscopy has been used to monitor gene expression and regulation in real time, revealing the complex interactions within these processes.

In the spirit of a shift in perspectives on cellular dynamicity, Martin Schwartz and his colleagues explain why mechanotransduction - whereby the cell communicates with the external environment through mechanical signals - should not be considered a switch-like process. Instead, they argue, the subcellular structures that mediate mechanotransduction continually change their structure and composition in response to the varying forces they experience.

One of the most dynamic cellular processes is the folding of proteins into distinct three-dimensional structures. This process is regulated by a formidable network of proteins, and breaks down in various diseases and in ageing. Ulrich Hartl and his co-workers discuss the role of chaperones in protein folding and proteome maintenance, focusing on ways in which their substrate proteins navigate the complex folding-energy landscape of the cellular environment.

Cellular processes are kept running smoothly by orchestrated movements of macromolecules. For instance, complexes in the nuclear membrane mediate the exchange of molecules between the nucleus and the cytoplasm. Robert Singer and his colleagues present models for how RNA is exported from the nucleus, using evidence obtained through single-molecule imaging.

This Insight includes reviews on some of the most exciting advances in cell biology. As always, Nature carries sole responsibility for all editorial content and peer review.

Deepa Nath, Senior Editor

Sadaf Shadan, Senior News \& Views Editor

\section{CONTENTS}

\section{REVIEW}

308 Central dogma at the single-molecule level in living cells G-W Li\&XSXie

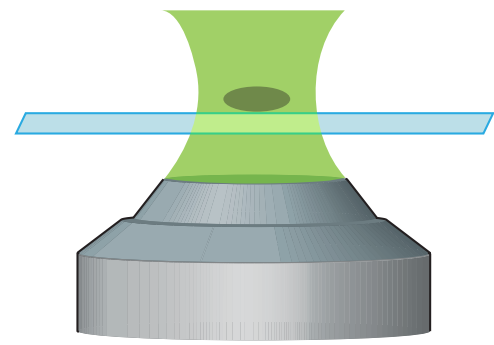

316 Dynamic molecular processes mediate cellular mechanotransduction B D Hoffman, C Grashoff \& M A Schwartz

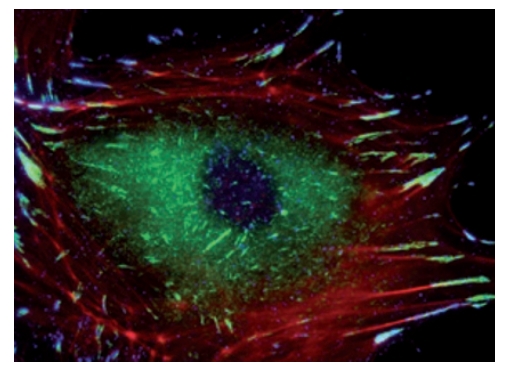

324 Molecular chaperones in protein folding and proteostasis FU Hartl, A Bracher \& M Hayer-Hartl

333 Nuclear export dynamics of RNA-protein complexes D Grünwald, RH Singer \& M Rout

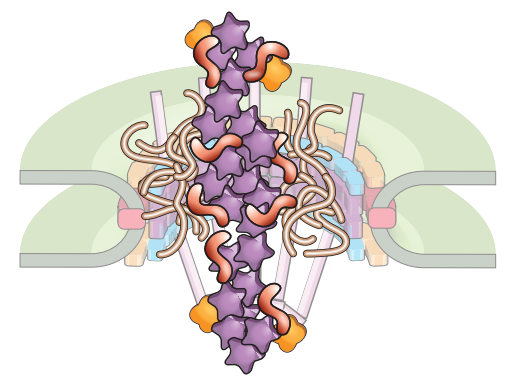

